\title{
A OFERTA DA FORMAÇÃO DE PROFESSORES EM EDUCAÇÃO FÍSICA NA MODALIDADE DE EDUCAÇÃO A DISTÂNCIA NO BRASIL
}

\author{
THE OFFER OF PHYSICAL EDUCATION TEACHER TRAINING ON \\ DISTANCE LEARNING IN BRAZIL
}

\section{LA OFERTA DE FORMACIÓN DE PROFESORES EN EDUCACIÓN FÍSICA EN LA MODALIDAD DE EDUCACIÓN A DISTANCIA EN BRASIL}

Rafael Teixeira da Silva1; Bruno Gawryszewski

\begin{abstract}
RESUMO
Este artigo apresenta uma análise sobre a oferta da formação de professores de Educação Física na modalidade da Educação a Distância (EaD), buscando cotejar sua expansão com as políticas educacionais e a participação do Estado como agente crucial na estratégia de expansão do ensino superior, especialmente para o setor privado. A metodologia de trabalho privilegiou a revisão bibliográfica sobre políticas de formação de professores por EaD e a extração de dados da Sinopse Estatística da Educação Superior dos anos de 2006, 2009, 2012, 2015 e 2017. Os resultados atestam a expansão contínua das matrículas por EaD nos cursos de Educação Física e que o crescimento tem se sustentado através das vagas ofertadas, sobretudo pela Universidade do Norte do Paraná (Unopar). O incremento dessa modalidade reforça a necessidade de aprofundamento nos estudos sobre um processo social que altera significativamente as formas de ensino e aprendizagem na educação superior e que cria um novo nicho de mercado para o setor privado, tutelado e estimulado pelas ações políticas do Estado.
\end{abstract}

PALAVRAS-CHAVE: Educação a Distância. Educação Física. Formação de professores.

\begin{abstract}
This article presents an analysis about the offer of physical education teacher training in the Distance Learning (DL) modality, seeking to compare its expansion with educational policies and the participation of the State as a crucial agent in the strategy of expansion of higher education, especially for the sector private. The work methodology focused on the literature review on teacher education policies by DL and the extraction of data from the Statistical Synopsis of Higher Education in the years 2006, 2009, 2012, 2015 and 2017. The results attest to the continuous expansion of enrollment by DL in the courses of Physical Education and that growth has been sustained through the vacancies offered, mainly by the University of North of Paraná (Unopar). The increase of this modality reinforces the need to deepen the studies on a social process that significantly changes the forms of teaching and learning in higher education and that creates a new niche market for the private sector, protected and stimulated by the political actions of the State.
\end{abstract}

KEYWORDS: Distance Learning. Physical Education. Teacher Training.

\footnotetext{
${ }^{1}$ Graduação em Educação Física - Universidade Federal do Rio de Janeiro (UFRJ). Rio de Janeiro, RJ - Brasil. E-mail: rafaelsilva.ufri@gmail.com

${ }^{2}$ Doutor em Educação - Universidade Federal do Rio de Janeiro (UFRJ). Rio de Janeiro, RJ - Brasil. Professor da Faculdade de Educação - Universidade Federal do Rio de Janeiro (UFRJ). Rio de Janeiro, RJ - Brasil. E-mail: brunogawry@gmail.com
}

Submetido em: 29/03/2018 - Aceito em: 25/02/2019

(C) ETD-Educação Temática Digital Campinas, SP $\quad$ v.21 n.3 $\quad$ p.760-781 jul./set. 2019 


\section{RESUMEN}

Este artículo presenta un análisis sobre la oferta de la formación de profesores de educación física en la modalidad de Educación a Distancia (EaD), buscando cortejar su expansión con las políticas educacionales y la participación del Estado como agente crucial en la estrategia de expansión de la enseñanza superior, especialmente para el sector privado. La metodología de trabajo privilegió la revisión bibliográfica sobre políticas de formación de profesores por EaD y la extracción de datos de la Sinopsis Estadísticas de la Enseñanza Superior de los años de 2006, 2009, 2012, 2015 y 2017. Los resultados demuestran la expansión continua de las matrículas por EaD en los cursos de Educación Física y que el crecimiento se ha sostenido a través de los cupos ofrecidos, sobre todo por la Universidad del Norte de Paraná (Unopar). El incremento de esta modalidad refuerza la necesidad de profundizar en los estudios sobre un proceso social que cambia las formas de enseñanza y aprendizaje en la educación superior y que crea un nuevo tipo de mercado para el sector privado, tutelado y estimulado por las acciones políticas del Estado.

PALABRAS CLAVE: Educación a Distancia. Educación Física. Formación de profesores.

\section{INTRODUÇÃO}

A presença da tecnologia digital (ou, também, digital-molecular) tem impacto profundo nas relações sociais. Se, no passado, essa tecnologia parecia estar confinada somente aos grandes investimentos industriais, atualmente está presente no cotidiano das pessoas, inclusive modificando substancialmente o modo de reprodução da vida humana. Também nos parece importante salientar que a tecnologia, apesar de se constituir enquanto força motriz, não o é independente de um modo de produção balizador, no caso o capitalismo, que, por sua vez, na medida em que tem como parâmetro central a apropriação privada da riqueza produzida, o consequente desenvolvimento de tecnologias, ainda que possa resultar em soluções para a humanidade, também amplia os campos de extração de mais riqueza.

A educação é um desses campos onde a tecnologia tem sido implementada de forma massiva, em especial no ensino superior via modalidade a distância, denominada como Educação a Distância (EaD), que é uma modalidade educacional na qual a mediação didático-pedagógica nos processos de ensino e aprendizagem ocorre com a utilização das denominadas Tecnologias de Informação e Comunicação (TICS), com estudantes e professores desenvolvendo atividades educativas em lugares ou tempos diversos.

Essa modalidade de ensino foi institucionalizada no Brasil em 1996 pela Lei de Diretrizes e Bases da Educação Nacional e, desde então, foram exaradas uma série de normas para regulamentá-la e conferir maior segurança jurídica para sua oferta e, consequentemente, a fim de favorecer a exploração desse novo mercado.

Desde então, a formação de professores tem sido alavancada pela profusão de vagas por EaD e, sobretudo, pelos subsídios estatais na expansão do ensino superior privado, sob a argumentação da urgência que o Brasil tem de qualificar esses profissionais, ainda tão 
numerosos na Educação Básica ${ }^{3}$ sem a graduação em nível superior ou sem a formação adequada à disciplina em que lecionam.

Levando em conta os dados de 2017 do Censo da Educação Superior (INEP, 2018), os cursos na área geral de Educação totalizam 745.611 matrículas por meio de EaD. Desse total, o curso de Pedagogia é disparado aquele com o maior quantitativo (430.115), seguido pela formação de professores de Educação Física (74.498), a sétima colocação na classificação geral dentre os cursos de graduação a distância.

Sendo assim, o trabalho tem como propósito analisar a evolução dos cursos de licenciatura em Educação Física ofertados na modalidade de Educação a Distância, associando ao próprio crescimento dos cursos presenciais em Educação Física e levando em conta as políticas estatais para a formação de professores. Para dar conta dessa tarefa, foram levantados dados do Instituto Nacional de Estudos e Pesquisas Educacionais (INEP), correspondentes ao Censo da Educação Superior dos anos de 2006, 2009, 2012, 2015 e 2017. Os dados extraídos para analise foram: cursos ofertados, vagas, ingressantes, concluintes e matriculas.

\section{A EAD E A FORMAÇÃO DE PROFESSORES}

Embora não no ritmo previsto pelas legislações educacionais, o ensino superior brasileiro tem se expandido ano após ano. De acordo com dados do Censo da Educação Superior divulgados anualmente, desde 2015 foi ultrapassado o contingente de oito milhões de matrículas, totalizando em 2017,8.286.663 para sermos mais exatos. Desse total, $24,68 \%$ das matrículas estão concentradas nas instituições públicas (2.045.356) e 75,32\% nas instituições privadas (6.241.307) (INEP, 2018).

A predominância de matrículas nas instituições privadas tem larga contribuição da modalidade EaD. O mesmo censo educacional atesta que em 2017 havia 1.756 .982 de matrículas por EaD no ensino superior. Desse total mencionado, as matrículas em instituições privadas perfaziam 1.591 .410 (90,58\%) contra 165.572 nas instituições públicas. Ou seja, trata-se de dizer que as matrículas por EaD abrangem $24,68 \%$ de estudantes no ensino superior (INEP, 2018).

A situação de predomínio e expansão do setor privado no ensino superior, acrescido ao estímulo da educação à distância, foram apontadas por Barreto e Leher (2008, p.432) como parte das prescrições políticas dos organismos internacionais direcionadas aos países periféricos e emergentes:

\footnotetext{
${ }^{3}$ De acordo com o Censo Escolar da Educação Básica de 2016, 22,5\% dos professores que atuam na Educação Básica não possuem formação em nível superior, totalizando 494.107 docentes (INEP, 2017).
}

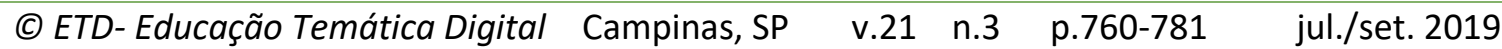


[...] outras mudanças congruentes com a agenda do BM, como a educação à distância, que vive um verdadeiro boom neste início dos anos 2000. O BM, a UNESCO e a $\mathrm{OMC}^{4}$ sustentam seu suposto caráter revolucionário. Ao mesmo tempo, os governos da América Latina e do Brasil em particular apressam sua regulamentação com vistas à institucionalização dessa "modalidade" de curso.

A normatização da Educação a Distância no Brasil se amparou em algumas premissas, tais como a de ser ofertada a um custo mais baixo que os cursos presenciais, por supostamente oferecerem uma inclusão digital e pela própria expansão em si do acesso ao ensino superior. As premissas acima tomaram impulso legal na ordem do Estado quando, em 1995, foi criada a Secretaria de Educação a Distância (SEED) no âmbito do Ministério da Educação. No entanto, um ano depois, o artigo 80 da Lei de Diretrizes e Bases da Educação de 1996 (LDB) traz de maneira clara que o poder público teria como papel importante incentivar, regulamentar e credenciar instituições de ensino que viessem a oferecer essa modalidade de ensino. Também na mesma lei, o artigo 32 menciona que a EaD poderá ser utilizada no ensino fundamental, como complementação de aprendizagem (BRASIL, 1996).

A Educação a Distância passa a ter um papel mais definido quanto aos seus objetivos na educação, após o decreto n. 2.494, de 10 de fevereiro de 1998, que veio regulamentar o artigo 80 da LDB (BRASIL, 1998), trazendo a definição mais precisa do objeto e também tratando dos órgãos que deveriam credenciar e regulamentar as instituições de ensino, inclusive as instituições para tal, o que abriu caminho para a institucionalização da EaD no país. A partir de então, a EaD ganhou mais corpo normativo no país, com o propósito de não ser uma oferta de ensino utilizada apenas como subsídio e complementação ao ensino presencial, e passaria a ser colocada como uma modalidade de ensino independente, que viria a ganhar força especialmente no ensino superior.

Com o incremento regulamentar da EaD, não tardou que a formação de professores fosse incluída como um dos cursos mais presentes nessa modalidade. Sob pretexto de atender à demanda histórica de formação de professores em nível superior, a movimentação no sentido de criar as bases normativas para tal finalidade foi reforçada justamente no contexto de expansão das matrículas na Educação Básica no final da década de 1990. É com base nesses argumentos que Malanchen (2007, p.130) ressalta que:

[...] a formação de professores realiza-se por meio da modalidade de EAD principalmente para os profissionais em exercício que atuam no Ensino Fundamental e Médio. Neste movimento, as TIC aparecem incisivamente e são citadas em todos os documentos legais expedidos pelo MEC como estratégias de viabilização da modalidade de EAD, coadunando com discurso de OI [organismo internacional, inclusão nossa].

\footnotetext{
${ }^{4}$ Siglas para Banco Mundial, Organização das Nações Unidas para a Educação, a Ciência e a Cultura e Organização Mundial do Comércio, respectivamente.
}

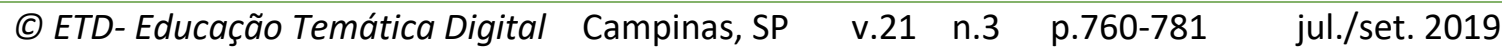


A partir de então, as ações do governo federal, sobretudo por meio do Ministério da Educação, incidiram em elevar a EaD como modalidade prioritária para a formação de professores, tanto nas legislações para o campo educacional como nos (muitos) programas. Tendo em vista as diversas iniciativas, destacaremos apenas algumas.

A começar pelo Plano Nacional de Educação (2001-2010), a Lei ํo 10.172/2001, que destinou o capítulo 6 para estabelecer diretrizes, objetivos e metas para a implementação dessa modalidade de educação e que a EaD seria um instrumento de democratização e de formação e capacitação de professores em serviço. No item "Objetivos e Metas", destacamse, dentre outros, a ênfase de que logo após a aprovação do PNE fosse iniciada a oferta de cursos a distância em nível superior para os professores da Educação Básica (BRASIL, 2001).

Vale ressaltar também a importância de iniciativas posteriores, como a Universidade Aberta do Brasil (UAB). Instituído pelo governo federal por meio do decreto no 5.800/2006, preferencialmente voltava-se para a formação inicial e continuada de professores e capacitação para gestores e trabalhadores da educação básica. Não temos condições de adentrar numa discussão detalhada sobre o funcionamento e propósitos do programa, mas nos parece relevante mencionar que a UAB foi um forte propulsor da formação de professores por EaD. Em 2012, foram totalizadas 449.966 matrículas nos cursos de licenciatura na modalidade EaD. Desse total mencionado, 128.196 (28,49\%) era matrículas da $U A B, o$ que atesta o entendimento de que se tratava de uma iniciativa política para certificação em massa, próprio da analogia do programa que se autodenominava "fábrica de professores" (MANDELI, 2017).

Outra ação que destacamos foi o Programa Pró-Licenciatura (Programa de Formação Inicial para Professores em exercício no Ensino Fundamental e no Ensino Médio), que tinha o propósito de conferir formação inicial aos profissionais que já exercessem o trabalho docente, nos seguintes casos: que estivessem em situação de não possuir a formação de licenciatura na disciplina na qual lecionavam; que tivessem o curso de bacharelado naquela respectiva área; ou que sequer tivessem o ensino superior. Não encontramos dados quantitativos confiáveis referentes ao número de professores formados, mas o programa foi absorvido pelo sistema $U A B$, o que contribui para uma ação mais específica quanto ao incremento da formação de docentes por EaD.

Todas essas legislações e programas até então implantados, trazem um novo olhar e direcionamento para a formação do professor, que passa por uma concepção de formação muito simplificada, tendo em vista as condições pelas quais são formados estes profissionais. No sistema UAB, os cursos ocorrem por meio de oferecimento por parte de uma instituição de ensino (pública, privada ou por meio de um consórcio misto) e o ente federado (estado ou município) que disponibilizavam a estrutura física do curso, os

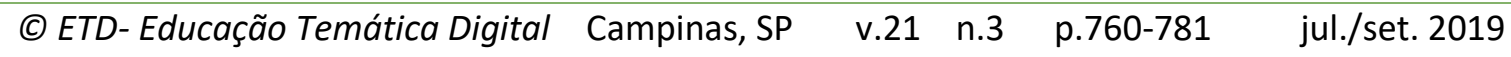


chamados polos presenciais que, frequentemente, não oferecem equipamentos adequados para serem considerados como polos de ensino. $E$ isso se reflete no tipo de profissional que vai atuar na educação, e consequentemente na qualidade do ensino. Para a compreensão melhor dessa questão, Freitas (2007, p.1206) diz que:

A ação do Estado nas políticas de formação, em resposta aos desafios enfrentados pela juventude, vem se caracterizando pela fragmentação, assegurando, conseqüentemente, dimensões diferenciadas de profissionalização com aprimoramento em cada um desses espaços, diferenciando os conhecimentos científicos, técnicos e culturais oferecidos. Aos estudantes de licenciaturas, oriundos da escola pública, são concedidas bolsas PROUNI, em instituições privadas, em cursos de qualidade nem sempre desejável, ou programas de formação nos pólos municipais da Universidade Aberta do Brasil (UAB), intensificando o reforço às IES privadas, em detrimento do acolhimento massivo da juventude nas licenciaturas das instituições públicas.

Essas iniciativas ocultam a desigualdade existente entre instituições de ensino e instituições de pesquisa, estudantes que estudam e pesquisam e estudantes que trabalham, reproduzindo a desigualdade educacional. Portanto, trata-se de compreender que os problemas históricos da não-realização do Estado em prover uma educação pública de qualidade são de ordem estrutural e não conjuntural, como muitas vezes é tratado. Formam-se profissionais de maneira aligeirada para tentar preencher essa lacuna na educação, e cria-se outro problema, que é a formação precária e esvaziada destes profissionais da educação. E sobre essa questão, Helena de Freitas entende que se evidencia assim um divórcio entre as necessidades atuais da escola e de profissionalização da juventude e um sistema de educação que não oferece possibilidades que venham habilitar os jovens para a vida do trabalho nas escolas públicas (FREITAS, 2007).

\section{A FORMAÇÃO EM EDUCAÇÃO FÍSICA}

Diante das mudanças no cenário educacional brasileiro discutido até então, a Educação Física também entra nesse contexto, com discussões comuns a todas as outras áreas do conhecimento, além de algumas questões mais específicas do próprio curso e formação. No que tange à Educação Física, parece-nos que a maior controvérsia reside na fragmentação da formação entre Bacharelado e Licenciatura, o que, em tese, delimitaria o campo de atuação de cada profissional.

A existência de duas formações na área foi institucionalizada pela Resolução no 03/1987, do extinto Conselho Federal de Educação, permitindo a formação em Bacharelado e Licenciatura. A possibilidade de atuar como bacharel, portanto fora do magistério formal, se deu a partir da emergência do discurso da promoção de um estilo de vida saudável e do mercado de serviços das práticas corporais em academias de ginástica, clubes, hotéis, personal trainer, dentre outros. No entanto, conforme critica Nozaki (2004, p.159), os

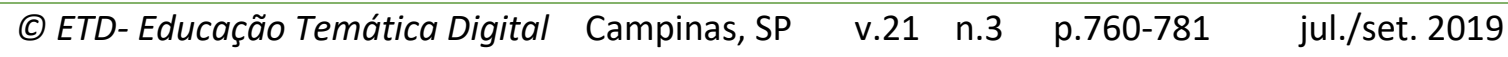


defensores da divisão do curso ocultaram que o campo não-escolar "trata-se do trabalho precário, desregulamentado e temporário, dimensão plus da estratégia atual do capital para intensificação da exploração da força de trabalho".

Em 1998, a Câmara de Ensino Superior, do Conselho Nacional de Educação, convocou a comunidade acadêmica para iniciar as discussões do processo de reformulação curricular. Assim, foi formada uma primeira comissão de especialistas de ensino com mandato de dois anos. Contudo, com a promulgação do Parecer CNE/CP 09/2001 referente às Diretrizes Curriculares Nacionais para a Formação de Professores de Educação Básica, o quadro foi modificado e determinava que a formação em licenciatura ministrada pelos cursos não poderia se confundir com a formação do bacharel e a discussão que se encaminhava para a reunificação, foi arrefecida.

A seguir, mais duas comissões de especialistas foram formadas e as principais forças que se defrontavam por dentro do aparelho de Estado estavam representadas pelo Conselho Federal de Educação Física (CONFEF, declaradamente a favor da divisão) e professores universitários respaldados pela entidade acadêmica do Colégio Brasileiro de Ciências do Esporte ( $C B C E$, que eram mais críticos à divisão). Para os que defendiam a divisão do curso, essa separação poderia vir a preparar melhor os profissionais que vão atuar na escola, onde este poderá dar mais ênfase na sua formação como docente, e o mesmo ocorreria para aqueles que vão atuar fora do ambiente escolar. Já os favoráveis à unificação entendiam que o professor de Educação Física tem como objeto de estudo a cultura corporal (algumas correntes teóricas vão acrescentar a expressão "do movimento") e que possui bases pedagógicas que lhe dão condições de atuar em qualquer campo, tanto na escola como fora do ambiente escolar.

Até que, nos dias 15 e 16 de dezembro de 2003, foram realizadas em Brasília duas audiências públicas onde foi apresentada a proposta construída num suposto consenso entre o Ministério da Educação/Secretaria de Ensino Superior, o CONFEF e o CBCE. Apesar dos embates teórico-metodológicos levados adiante por setores do campo acadêmico ligados ao Movimento Nacional contra a Regulamentação do Profissional de Educação Física (MNCR) e sindicatos de professores e o Movimento Estudantil de Educação Física que denunciaram o restrito processo de discussão e a formação fragmentada, o "consenso possível"5 foi vitorioso e instituída a Resolução no 07/2004, como diretriz formativa que orienta a organização do currículo de Educação Física (AUTOR, 2008).

Entendemos que essa fragmentação pode comprometer a formação do professor a uma "epistemologia da prática", em que a prática docente se respalde apenas pelas

\footnotetext{
${ }^{5}$ Expressão que ficou famosa na época da aprovação das Diretrizes Curriculares.

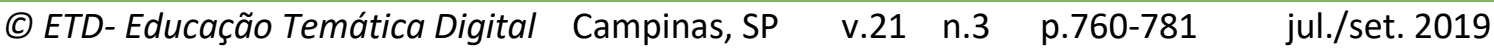


experiências vividas, especialmente quando esse novo profissional, no intuito de atender a demandas mercadológicas, é convocado a mostrar suas competências como "trabalhador contemporâneo", como ser comunicativo, pró-ativo e flexível. Nesse caso, a competência no sentido de uma formação reduzida, sem uma análise reflexiva daquilo que se apreende ao longo de uma formação, Sobrinho (2011, p.131) entende que:

\begin{abstract}
Sob a égide da competência, escolhe-se o que ensinar e como ensinar tomando como critério a sua imediaticidade prática que deve estar em todo conhecimento a ser adquirido. No que se refere à prática pedagógica, essa regra adquire o caráter de exclusão do processo de apropriação dos conhecimentos universais em troca de um método que representa uma pura reflexão empirista sobre a prática docente.
\end{abstract}

Ainda que de forma resumida, pudemos apresentar um pouco dos embates travados acerca das diretrizes formativas para a Educação Física. No entanto, ainda de modo pouco expressivo nas discussões acadêmicas, encontra-se a formação em cursos de graduação em Educação Física por EaD, embora essa modalidade de educação esteja crescendo em termos de oferta de vagas nas instituições de ensino superior, como será exposto na próxima seção.

\title{
4 A EXPANSÃO DOS CURSOS A DISTÂNCIA PARA FORMAÇÃO DE PROFESSORES DE EDUCAÇÃO FÍSICA
}

Primeiramente, realizamos uma procura pelas produções que tenham abordado a graduação em Educação Física por EaD a partir das palavras-chave "educação física" e "educação a distância" no intuito de realizar um balanço teórico e compreender de que forma poderíamos contribuir para a consecução da discussão. As bases consultadas foram produções aleatórias filtradas pelo "Google Acadêmico", procura direta em periódicos tradicionais da área da Educação Física e os anais de 2013 e 2015 do Congresso Brasileiro de Ciências do Esporte.

Encontramos alguns artigos que desenvolviam reflexão sobre o uso de TICs nas aulas da disciplina ou sobre ensino de determinadas práticas corporais em cursos de Licenciatura em Educação Física por EaD. Embora importantes para compreender uma totalidade, não será considerado para efeitos de revisão teórica neste artigo.

Como resultado das buscas, pudemos perceber que, com exceção do artigo de Anversa et. al. (2017), produção escrita por pesquisadores do Paraná e com foco na compreensão se a prática reflexiva é contemplada em cursos de Educação Física por EaD, as produções encontradas e com maior proximidade no debate teórico à proposta do presente texto (oito artigos publicados em periódicos e uma dissertação de mestrado na Universidade de Brasília) estão circunscritas a um grupo de pesquisadores da Região CentroOeste, vinculados à Universidade Federal de Goiás (UFG) e à Universidade de Brasília (UnB). Dentre os nove textos selecionados, destacaremos para efeitos de revisão teórica mais detida, três deles, sendo que em todos esses tiveram a participação da pesquisadora

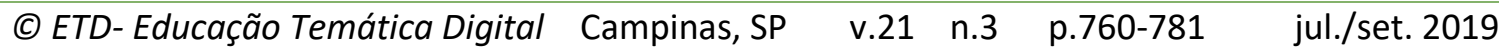


Fernanda Cruvinel Pimentel, Doutora em Educação pela UnB e professora do Centro de Ensino e Pesquisa Aplicada à Educação da UFG.

No texto de 2015, Cruvinel et al. (2015) discutiram o tema a partir do recorte sobre como o curso de licenciatura em Educação Física estava sendo desenvolvido pela UFG através do sistema da UAB. A pesquisa em questão foi caracterizada pelos autores como sendo de perspectiva diagnóstica descritivo-exploratória, realizada por meio de análise documental e entrevistas semiestruturadas com participantes do curso (gestores, professores, tutores e estudantes). Resumidamente, os autores elencam que a dinâmica do curso, com o passar do tempo, incorporou mais encontros presenciais nas disciplinas de caráter teórico-práticas e que o letramento digital e a flexibilidade de horários, favoreceram a democratização do ensino superior. Em relação aos problemas do curso, os autores destacaram a falta de estrutura adequada nos polos presenciais, a falta de domínio dos trabalhadores com todas as possibilidades das TICs e a intensificação do trabalho docente (CRUVINEL ET AL, 2015).

Um ano antes, Pimentel et al (2014) publicaram uma análise sobre a experiência do curso de Educação Física da Universidade de Brasília, também pelo sistema da UAB. Tratouse de um estudo de caso, de tipo descritivo-exploratório, em que foram executados como procedimentos metodológicos a pesquisa documental, entrevista semiestruturada com 11 sujeitos participantes do curso e aplicação de questionário aos egressos do curso da primeira turma. O balanço que os autores destinam ao curso da UnB é que, embora ocorram dificuldades no que tange ao trabalho docente dos professores e tutores, a falta de institucionalização da modalidade $\mathrm{EaD}$ na universidade e a não efetivação de propostas metodológicas e conceituais, o curso teria uma formação de qualidade, pautada em discussões críticas e valorização dos encontros presenciais, no sentido de articular as dimensões teóricas e práticas (PIMENTEL ET AL, 2014).

No entanto, a produção que mais se aproxima dos propósitos do presente artigo, foi escrita em 2013 por Pimentel et al $(2013)^{6}$. A partir de dados extraídos do Censo da Educação Superior do INEP de 2011 e informações dos sistemas da UAB e do e-MEC, o texto em questão organizou um mapeamento da oferta de cursos de Educação Física pela modalidade EaD. Na época, os autores identificaram 28 cursos de Educação Física por EaD e esses cursos totalizavam apenas 4.976 matrículas e constataram que, embora ocorresse predominância de oferta de cursos pelo setor público (24 públicos contra 4 por instituições privadas), sobretudo em função do impulso proporcionado pela UAB, 45,82\% das matrículas estavam fora do sistema UAB, o que sugere a concentração de matrículas no setor privado

\footnotetext{
${ }^{6}$ No mesmo ano, Pimentel e Mascarenhas (2013) apresentaram texto muito semelhante no XVIII Congresso Brasileiro de Ciências do Esporte. Por isso, optamos por fazer a resenha de apenas um dos textos.
}

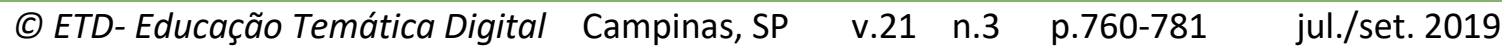


em poucas instituições. Por fim, até 2011, apenas 194 pessoas tinham concluído o curso em Educação Física.

Tendo em vista a ainda limitada produção teórica, lançamo-nos ao desafio de ampliar o debate sobre a Educação Física por EaD, mas com foco na evolução da oferta de cursos por essa modalidade, sobretudo levando em conta, conforme já dito, que o curso de Licenciatura em Educação Física, em 2017, foi o segundo colocado dentre as formações que mais ofertaram matrículas para a formação de professores e oitavo na classificação geral, diferente dos dados apresentados por Pimentel et. al (2013), em que a Educação Física na época não tinha quantitativo significativo.

A realização da pesquisa teórico-empírica se deu, prioritariamente, com a consulta à base de dados do Censo da Educação Superior/INEP. A análise da expansão tem como recorte inicial o ano de 2006, pois se deu com a instauração do primeiro curso de Licenciatura em Educação Física por EaD. Além do mais, destacam-se os fatos de ter sido o ano imediatamente posterior ao decreto no 5.622/2005 (exarado em dezembro de 2005) que reforçou a regulamentação da EaD na LDB e por ser o ano da consolidação do sistema da UAB com o decreto № 5.800/2006 (BRASIL, 2005; BRASIL, 2006). Portanto, nossa análise cobriu o período entre 2006 e 2017, ano do último censo realizado do ensino superior, no momento da escrita do texto. Além dos anos de 2006 e 2017, incluiremos dados referentes aos anos de 2009, 2012 e 2015 para possibilitar percepção histórica da análise. Os dados extraídos e analisados serão os seguintes: quantitativo de cursos, vagas ofertadas, matrículas, ingressos e concluintes.

A partir da extração desses dados, foram produzidas tabelas com o objetivo de expor a evolução da modalidade de educação a distância em cursos de Educação Física, ao passo que realizamos também cotejamento da oferta dos cursos presenciais e a natureza jurídica das instituições.

De acordo com o sistema e-MEC do Ministério da Educação, 27 instituições estavam autorizadas a ofertar vagas para cursos de Educação Física na modalidade a distância no ano de 2015 (a saber, não necessariamente todas as vagas são preenchidas). Destacamos as três maiores instituições de vagas do ensino público e três do ensino privado, como segue na tabela abaixo.

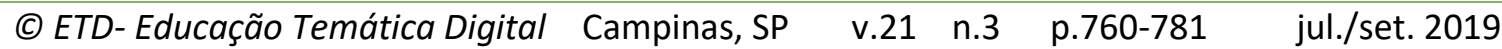


Quadro 1 - Autorização de vagas em cursos de Licenciatura em Educação Física na modalidade a distância no Brasil no ano de 2015, no ensino público e privado.

\begin{tabular}{|c|c|l|c|}
\hline Natureza Jurídica & $\begin{array}{c}\text { No vagas } \\
\text { autorizadas }\end{array}$ & \multicolumn{1}{|c|}{ Natureza Jurídica } & $\begin{array}{c}\text { № vagas } \\
\text { autorizadas }\end{array}$ \\
\hline Pública & 754 & $\begin{array}{l}\text { Privada } \\
\text { Universidade Norte do } \\
\text { Paraná - Unopar }\end{array}$ & 46.900 \\
\hline $\begin{array}{c}\text { Universidade Federal do } \\
\text { Espírito Santo }\end{array}$ & 470 & $\begin{array}{l}\text { Centro Universitário } \\
\text { Leonardo da Vinci }\end{array}$ & 4.200 \\
\hline $\begin{array}{c}\text { Universidade Federal do Rio } \\
\text { Grande do Norte }\end{array}$ & 460 & $\begin{array}{l}\text { Instituto Superior de } \\
\text { Teologia Aplicada }\end{array}$ & 2.000 \\
\hline Universidade de Brasília & $\mathbf{1 . 6 8 4}$ & \multicolumn{2}{|c|}{} \\
\hline Total de Vagas Ofertadas & &
\end{tabular}

Fonte: Elaboração própria, Sistema e-MEC 2015 - MEC

Percebe-se na tabela acima que as três maiores instituições do ensino público nessa modalidade de ensino estavam autorizadas a ofertar em 20151.684 vagas, enquanto somente as três principais instituições do ensino privado somaram juntas 53.100 vagas, uma diferença acentuada. Das vagas centralizadas no ensino privado, torna-se importante ressaltar que, das vagas oferecidas, 46.900 pertencem a Universidade Norte do Paraná (Unopar), evidenciando também uma concentração de vagas no ensino privado e em uma instituição de ensino, o que corresponde a pouco mais de $88,3 \%$. A seguir, expomos informações sobre os cursos de Educação Física no ensino presencial. 
TABELA 1 - Cursos de Licenciatura em Educação Física no ensino presencial no Brasil em 2006, 2009, 2012, 2015 e 2017.

\section{Quantidade de Cursos Presenciais de Educação Física}

\begin{tabular}{|c|c|c|c|c|c|c|c|c|c|c|}
\hline & \multicolumn{2}{|c|}{2006} & \multicolumn{2}{|c|}{2009} & \multicolumn{2}{|c|}{2012} & \multicolumn{2}{|c|}{2015} & \multicolumn{2}{|l|}{2017} \\
\hline & Público & Privado & Público & Privado & Público & $\begin{array}{c}\text { Privad } \\
\text { o }\end{array}$ & Público & $\begin{array}{c}\text { Privad } \\
\text { o }\end{array}$ & $\begin{array}{c}\text { Públic } \\
0\end{array}$ & $\begin{array}{c}\text { Privad } \\
0\end{array}$ \\
\hline Universidades & 132 & 99 & 101 & 120 & 168 & 152 & 167 & 146 & 140 & 150 \\
\hline $\begin{array}{c}\text { Centro } \\
\text { Universitário }\end{array}$ & 1 & 50 & 4 & 64 & 7 & 89 & 5 & 91 & 5 & 112 \\
\hline $\begin{array}{l}\text { Faculdades } \\
\text { Integradas }\end{array}$ & 3 & 9 & 0 & 0 & 0 & 0 & 0 & 0 & 0 & 0 \\
\hline $\begin{array}{l}\text { Faculdades, } \\
\text { Escolas e } \\
\text { Institutos }\end{array}$ & 9 & 82 & 8 & 123 & 15 & 210 & 12 & 230 & 13 & 236 \\
\hline $\begin{array}{l}\text { Centros de } \\
\text { Educação } \\
\text { Tecnológica }\end{array}$ & 2 & 0 & 2 & 0 & 7 & 0 & 10 & 0 & 11 & 0 \\
\hline Total & 147 & 240 & 115 & 307 & 197 & 451 & 194 & 467 & 169 & 498 \\
\hline
\end{tabular}

Fonte: Elaboração própria, adaptado de Sinopse Educação Superior 2006/2009/2012/2015/2017 INEP

Os dados indicam que de 2006 para 2017, o setor privado teve um aumento expressivo em comparação ao setor público nos cursos de Licenciatura em Educação Física, levando em considerações os cursos ofertados pelas instituições de ensino superior. Percebe-se que houve constante crescimento na quantidade de cursos presenciais na rede privada de ensino superior. Em 2006, foram oferecidos 240 cursos de Educação Física, já no ano de 2015 , esse número era de 498 , crescimento de $107,5 \%$.

Na tabela acima, percebe-se que o crescimento de cursos presenciais no ensino superior público não foi tão acentuado como no ensino privado. Em 2006, foram contabilizados 147 cursos de Educação Física na esfera pública. Em 2015, esse número saltou para 169 cursos, crescimento de pouco mais de 14,96\%. Chama a atenção a expressiva redução do número de cursos mantidos por instituições públicas de ensino superior entre 2015 e 2017, interrompendo uma trajetória de crescimento, fato que abre margem a investigação sobre os motivos que levaram tão drástica redução quantitativa. 
Também foi possível perceber que a concentração de cursos na esfera pública se dá nas Universidades. Em 2006, haviam 132 cursos, de um total de 147. Já no ano de 2015, foram 140 cursos, de um total de 169. Na esfera privada, a concentração de cursos em 2006 se deu nas Faculdades Integradas, , com 82 vagas em um total de 240. Já em 2017, a concentração se deu nas Faculdades, Escolas e Institutos, com 236 cursos de um total de 498.

TABELA 2 - Cursos de Licenciatura em Educação Física no ensino a distância no Brasil em 2006, 2009, 2012, 2015 e 2017.

\section{Quantidade de Cursos a Distância de Educação Física}

\begin{tabular}{lllll}
\hline 2006 & 2009 & 2012 & 2015 & 2017
\end{tabular}

Público Privado Público Privado Público Privado Público Privado Público Privado

\begin{tabular}{|c|c|c|c|c|c|c|c|c|c|c|c|}
\hline Universidades & 0 & & 1 & 2 & 3 & 27 & 3 & 12 & 4 & 13 & 8 \\
\hline $\begin{array}{c}\text { Centro } \\
\text { Universitário }\end{array}$ & & 0 & & 0 & 1 & 0 & 1 & 0 & 2 & 0 & 9 \\
\hline $\begin{array}{l}\text { Faculdades } \\
\text { Integradas }\end{array}$ & & 0 & & & & & & 0 & 1 & 0 & 0 \\
\hline $\begin{array}{c}\text { Faculdades, } \\
\text { Escolas e } \\
\text { Institutos }\end{array}$ & & 0 & & & & & & & & 0 & 0 \\
\hline $\begin{array}{l}\text { Centros de } \\
\text { Educação } \\
\text { Tecnológica }\end{array}$ & & 0 & & & & & & & & 0 & 0 \\
\hline Total & 0 & & 1 & 2 & 4 & 27 & 4 & 12 & 7 & 13 & 17 \\
\hline
\end{tabular}

Fonte: Elaboração própria, Sinopse Educação Superior 2006/2009/2012//2015/2017 - INEP

Conforme verificado na Tabela 2, na Educação a Distância constata-se um quadro inverso ao apresentado no ensino presencial, onde se percebe que a maior oferta de cursos de Educação Física nessa modalidade se dá na esfera pública, mais especificamente nas Universidades. 
A tabela acima indica que, em 2006, as instituições públicas de educação superior não ofertavam cursos na modalidade a distância e em 2009, apenas dois cursos em universidades. Conforme exposto, o grande salto quantitativo de cursos ocorreu de 2009 para 2012, ocasião em que estavam em vigência 27 cursos em instituições públicas, possivelmente todos vinculados ao sistema UAB. Contudo, em 2015, o quantitativo decresceu para 12 cursos e, em 2017, subiu para 13 cursos, possível sintoma da fragilização do programa federal da modalidade EaD.

Na modalidade a distância no setor privado, foi inaugurado o primeiro curso de graduação em Educação Física, em 2006. Em 2015, verificou-se um total de apenas sete cursos, sendo quatro deles em universidades, o que, à primeira vista, poderia sugerir que houvesse um predomínio do setor público nessa modalidade. Somente em 2017 é que o setor privado ultrapassou em cursos o quantitativo das instituições públicas.

Tabela 3 - Número absoluto de matrículas em cursos de Licenciatura em Educação Física na modalidade de ensino presencial no Brasil nos anos de 2006, 2009, 2012 e 2015.

\begin{tabular}{|c|c|c|c|c|}
\hline \multicolumn{5}{|c|}{ Matrículas no Ensino Presencial Público e Privado } \\
\hline 2006 & 2009 & 2012 & 2015 & 2017 \\
\hline
\end{tabular}

\begin{tabular}{|c|c|c|c|c|c|}
\hline Pública & 25.090 & 22.104 & 33.655 & 32.964 & 32.113 \\
\hline Privada & 72.528 & 67.710 & 82.956 & 93.288 & 79.181 \\
\hline Total & $\mathbf{9 7 . 3 4 8}$ & $\mathbf{8 9 . 9 1 4}$ & 116.611 & 126.252 & 111.294 \\
\hline
\end{tabular}

Fonte: Elaboração própria, Sinopse Educação Superior 2006/2009/2012/2015/2017 - INEP

Verifica-se acima que o predomínio do setor privado no ensino superior nos cursos de Educação Física foi acompanhado de um crescimento na rede pública com um aumento de 7.023 matrículas (28\%). Com relação às instituições privadas do número de matrículas, de 2006 a 2015 foi verificado um aumento de 20.760 matrículas presenciais (28,62\%), seguido de uma expressiva queda de 14.107 matrículas nos últimos dois anos. 
No ensino a distância o quadro também é predominante na rede privada, como é possível observar na tabela 4 abaixo:

Tabela 4 - número absoluto de matrículas em cursos de Licenciatura em Educação Física na modalidade de ensino a distância no Brasil nos anos de 2006, 2009, 2012 e 2015.

\begin{tabular}{|c|c|c|c|c|c|}
\hline & & atrículas & a Distâr & e Privac & \\
\hline & 2006 & 2009 & 2012 & 2015 & 2017 \\
\hline Pública & $*$ & 1.101 & 3.232 & 1.657 & 2.357 \\
\hline Privada & $*$ & 565 & 3.043 & 39.759 & 72.141 \\
\hline Total & - & 1.666 & 6.275 & 41.416 & 74.498 \\
\hline
\end{tabular}

Fonte: Elaboração própria, Sinopse Educação Superior 2006/2009/2012/2015/2017 - INEP

Percebe-se acima que houve oscilação no número de matriculados no ensino a distância público, o auge se deu no ano de 2012, com 3.232 matriculados, já no ano de 2015 constatou-se uma queda na quantidade de matriculados que foi de 1.657 e mais um aumento em 2017, totalizando 2.357. Na rede privada é possível observar um constante crescimento, principalmente entre os anos de 2012 e 2017, onde se constatou um estrondoso salto de 3.043 para 74.498 matriculados.

Tal aumento tem como hipótese uma série de fusões e aquisições entre empresas educacionais que ocorreu nos últimos anos, sobretudo por empresas de capital aberto através de fundos de investimento, o que elevou o poder aquisitivo destas instituições e, consequentemente, seu poder de captação de alunos, expandindo suas ofertas.

Somando as matrículas da EaD nas redes pública e privada, tem-se o total de 74.498. Deste total, pouco mais de $96 \%$ pertencem à rede privada de ensino. Do total de matrículas nas instituições públicas e privadas, somadas a educação a distância como presencial, totaliza-se 185.792 matrículas em 2017, 38,82\% destas concentradas na EaD.

No entanto, para que possamos ter uma melhor percepção de crescimento, é preciso que seja analisada também a quantidade de vagas que oferecem essas instituições, como também o número de ingressos, matrículas e o fluxo de saída do ensino superior, os concluintes.

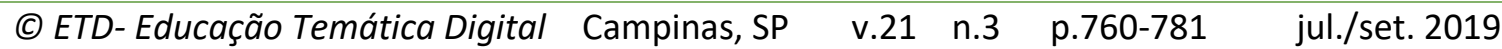


A tabela 5 mostra como vem se dando o ritmo de expansão das vagas e estudantes matriculados e concluintes nos cursos de Educação Física no ensino presencial nos anos de 2006, 2009, 2012, 2015 e 2017.

Tabela 5 - número absoluto de vagas, ingressos, matrículas e concluintes de Licenciatura em Educação Física no ensino presencial no Brasil em 2006, 2009, 2012, 2015 e 2017.

\section{Ensino Presencial Público e Privado}

\begin{tabular}{|l|l|l|l|l|}
\hline 2006 & 2009 & 2012 & 2015 & 2017 \\
\hline 52.222 & 56.833 & 71.662 & 78.199 & 75.704 \\
\hline 32.015 & 23.968 & 38.401 & 40.107 & 29.346 \\
\hline 97.618 & 89.814 & 116.611 & 126.252 & 111.294 \\
\hline 14.630 & 20.318 & 21.611 & 21.013 & 21.816 \\
\hline
\end{tabular}

Fonte: Elaboração própria, Sinopse Educação Superior 2006/2009/2012/2015/2017 - INEP

Como está exprimido, o número de vagas no ensino presencial em 2006 foi de 52.222, já no ano de 2015 foram ofertadas 78.199, crescimento de 49,7\%, seguido de uma queda em pouco mais de 2 mil vagas em 2017. Com relação ao número de ingressantes, houve oscilações ao longo dos anos, mas mesmo assim constatou-se crescimento quando comparados os anos de 2006 e 2015. Em 2006, foi de 32.015; no ano de 2015, o número foi de 40.107 , um crescimento de $25,2 \%$. No entanto, em 2017 , ocorreu uma expressiva queda de mais de 10 mil ingressos. Por fim, em se tratando do número de concluintes após um substantivo aumento de quase 50\% de 2006 para 2009, o quantitativo se estabilizou desde então, ainda que o número total de matriculados tenha oscilado significativamente no período mostrado. Ou seja, o total de concluintes não necessariamente segue uma trajetória linear proporcional ao número de matriculados, mas tem dinâmica própria.

Na modalidade a distância o crescimento foi proporcionalmente superior ao que se viu no ensino presencial, como será exposto na tabela 6: 
Tabela 6 - número absoluto de vagas, ingressos, matrículas e concluintes de Licenciatura em Educação Física na Educação a distância no Brasil em 2006, 2009, 2012, 2015 e 2017.

Ensino a Distância Público e Privado

\begin{tabular}{|lllll}
\hline 2006 & 2009 & 2012 & 2015 & 2017 \\
\hline
\end{tabular}

\begin{tabular}{|c|c|c|c|c|c|}
\hline Vagas & 80 & 1.654 & 3.742 & 36.884 & 51.865 \\
\hline Ingressos & 73 & 551 & 2.487 & 27.587 & 35.359 \\
\hline Matrículas & $*$ & 1.666 & 6.275 & 41.416 & 74.498 \\
\hline Concluintes & $*$ & 48 & 498 & 926 & 12.499 \\
\hline
\end{tabular}

Fonte: Elaboração própria, Sinopse Educação Superior 2006/2009/2012/2015/2017 - INEP

Verifica-se na tabela acima que, no ano de 2006, foi registrada uma oferta de 80 vagas; já em 2017 constatou-se a oferta de 51.865 vagas. Até o ano de 2012, o crescimento foi baixo, e a partir desse ano o salto na oferta de vagas foi bastante significativa, totalizando um aumento de 48.123 vagas. Na modalidade EaD, o crescimento proporcionalmente também foi maior ao referir-se ao número de ingressantes, já que, em 2006, foram constatados 73 ingressos e em 2017, esse número foi de 35.359. Com relação ao número de concluintes no ensino presencial, nota-se que no ensino a distância em, 2015,, mesmo com a já expressiva expansão naquele tempo histórico, apenas 926 pessoas concluíram curso de licenciatura em Educação Fìsica.Considerando a quantidade de matrículas dos anos anteriores, parece razoável aventar a hipótese de que existe uma evasão considerável nestes cursos de $\mathrm{EaD}$, considerando que se realizam as matrículas e, de três a quatro anos após, o aluno concluiria o seu curso.

Inicialmente, poderíamos relacionar o baixo número de formados no ensino a distância até 2015 pela provável alta taxa de desistência ao longo do curso, tendo em vista dificuldades que os alunos passam a ter, seja com relação a pagamento de mensalidades ou até mesmo a outras dificuldades de prosseguirem no curso, como falta de tempo para se dedicar a sua formação ou até mesmo as dificuldades de aprendizagem por falta de um acompanhamento pedagógico. Contudo, reconhecemos que as razões levantadas são apenas de natureza especulativa e demandariam uma pesquisa a respeito do assunto. Em um sentido parecido, mas referente a uma instituição pública de ensino, Lazzarotti Filho, Pasquali e Furtado (2015) identificaram o perfil sócio-demográfico dos egressos do curso de Educação Física da UFG pelo sistema UAB e apontaram que 134 estudantes concluíram o curso $(42,4 \%$ dos que iniciaram).

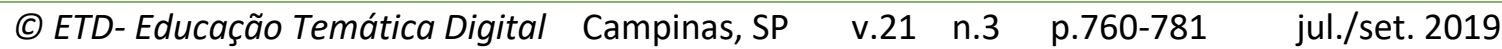


No ensino presencial, parece também haver discrepância, tendo em vista a taxa de matriculados e número de formandos. Diante dos dados apresentados, nota-se que o ensino a distância proporcionalmente vem crescendo mais que o ensino presencial. A rede pública apresenta uma quantidade maior de cursos, como foi apresentado. Já com relação ao número de vagas ofertadas e até mesmo de matrículas, a rede privada apresenta uma concentração considerável.

Sendo assim, o quadro que se tem quando comparamos o ensino presencial ao ensino a distância, ou até mesmo a evolução do ensino a distância no período temporal proposto, percebe-se que houve um aumento na oferta de cursos, de matrículas, vagas, ingressos e até mesmo no número de concluintes, embora este não tenha sido tão acentuado, isso podendo ser explicado pelo alto índice de evasão no ensino superior, tendo em vista as relações matrícula e concluintes.

No entanto, o Censo da Educação Superior em 2017 informa que o número de concluintes subiu para 12.499 pessoas. Tal desproporção do número de concluintes em um período de dois anos abre um campo de investigação para futuras pesquisas, pois este súbito aumento pode estar tanto ligado a fatores intrínsecos à própria dinâmica de acesso e permanência no ensino superior, quanto pode estar relacionado à fatores metodológicos equivocados na coleta de dados pelo INEP.

\section{CONSIDERAÇÕES FINAIS}

O trabalho buscou analisar como a modalidade de educação a distância tem se desenvolvido na formação de professores de Educação Física. Nesse sentido, entendemos que nos parece razoável discutir os parâmetros de qualidade que estão postos para a formação docente no Brasil, visto que esses profissionais deverão enfrentar muitos desafios ao iniciarem na profissão, na qual serão exigidas uma série de habilidades e saberes que vão além dos conhecimentos adquiridos, como afirma Giolo (2008, p.1228):

[...] irão enfrentar uma turma de alunos, vivos e presentes, reunidos numa escola, e, nesse ambiente, não serão exigidos apenas os conhecimentos adquiridos, mas um conjunto de saberes e habilidades (método adequado, equilíbrio emocional, comportamento ético, estratégias de domínio de classe, desinibição, liderança, paciência e etc.), coisas que se aprendem nos livros e, principalmente, na prática da convivência, na experimentação, nas cobranças mútuas, nos laboratórios, nos seminários, nas palestras, nos debates temáticos, nas apresentações culturais, nos estágios supervisionados, nas falas de salas de aulas, nos corredores, nos restaurantes universitários, etc.

Mais do que conhecimentos e domínio de conteúdos, o futuro professor precisa socializar, para que o futuro docente crie a sua autonomia e seja reflexivo, fazendo valer o seu papel de sujeito intelectual e não um "técnico" que simplesmente vai reproduzir conteúdos pré-estabelecidos em cartilhas. E no âmbito da EaD essa questão se torna

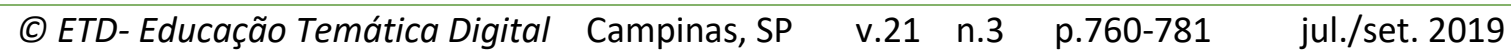


delicada, tendo em vista que está se formando profissionais da educação, aqueles possuem grande importância na sociedade e exercem um papel intelectual fundamental que contribui para as transformações sociais.

No entanto, como foi abordado ao longo do trabalho, a privatização do ensino superior tem restringido a concepção pública da educação, já que o Estado segue presente de modo menos relevante na educação superior pública e, em contrapartida, vem sendo "eficiente" junto à iniciativa privada através canalização de recursos como o Fundo de Financiamento Estudantil (FIES) e o Programa Universidade para Todos (ProUni). Isto explica não somente a expansão na quantidade de cursos, mas também de matrículas. Tal monta de recursos para a iniciativa privada, embora esteja inscrito como um direito social, implica também em sua caracterização como um serviço mercantil, um produto a ser vendido e intensificado através da modalidade $\mathrm{EaD}$, que se coloca até mesmo como um forte concorrente do modelo presencial de ensino, desvirtuando-se do propósito inicial deste modelo, como ressalta Giolo (2008, p.1217):

[...] em vez de ser uma modalidade de ensino capaz de ampliar o raio de atuação da educação superior para além da esfera abrangida pela educação presencial, tornou-se concorrente da presencial, ou melhor, para certos cursos, ela se constituiu numa ameaça, pois pode praticar preços menores, além de oferecer outras facilidades práticas ligadas ao tempo, ao espaço e aos métodos de aprendizagem.

O avanço das matrículas nas instituições privadas de ensino superior tem participação direta do Estado ocorre de modo concomitante aos cada vez mais minguados fundos para manutenção e desenvolvimento das instituições públicas, a despeito destas ainda persistirem como instituições de notória qualidade.

A grande questão para o debate sem dúvida passa pelo compromisso que estas instituições possuem com a educação brasileira. As instituições públicas ainda conseguem manter os pilares do ensino superior, que é a pesquisa, o ensino e a extensão, enquanto as instituições privadas, em sua grande maioria, destinam-se apenas à formação de profissionais instrumentalizados para o mercado de trabalho, tendo assim limitações quanto aos requisitos normais do ensino superior, historicamente composto pelos três pilares citados, que dão características e significado ao que de fato representa esse nível educacional.

Em vista às demandas do país, o ensino superior deve se constituir em um centro de produção de conhecimento que ajude a pensar e propor soluções para as grandes problemáticas e o desenvolvimento do país. A qualidade do ensino da formação intelectual dos professores não pode ser empobrecida, na medida em que traz consequências trágicas para a formação da própria sociedade.

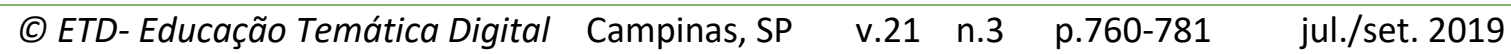


Cabe a reflexão sobre se a EaD pode vir a proporcionar esses elementos importantes no processo de formação do aluno, um percurso sólido com vivências práticas, com pesquisa, extensão e ensino de qualidade, sendo capaz de ir além da certificação em massa (o que não tem se confirmado até o momento, sobretudo nas instituições privadas). Também questionamos a prioridade dada à expansão da formação de professores justamente por meio de programas por essa modalidade. Parece que, ao optar por essa via de formação, entendem que a questão educacional vai ser superada apenas com a certificação em massa. Se esta for a via, estaremos mal.

\section{REFERÊNCIAS}

ANVERSA, Ana Luiza B. et al. A prática reflexiva na formação de professores de Educação Física na modalidade EAD. Revista Brasileira de Ciência e Movimento. Brasília, v.25, n.2, p.122-136, 2017.

BARRETO, Raquel Goulart; LEHER, Roberto. Do discurso e das condicionalidades do Banco Mundial, a educação superior "emerge" terciária'. Revista Brasileira de Educação, Rio de Janeiro, v. 13 n. 39, p. 423-436, set./dez. 2008.

BRASIL. Lei no 9.394, de 20 de dezembro de 1996. Estabelece as diretrizes e bases da educação nacional. Diário Oficial da União, Brasília, DF, 23 dez. 1996. Disponível em: http://www.planalto.gov.br/ccivil 03/leis/L9394.htm Acesso em: 5 dez. 2017.

BRASIL. Decreto no 2.494, de 10 de fevereiro de 1998. Regulamenta o artigo 80 da LDB. Lex: Brasília, 1998. Disponível em:

http://portal.mec.gov.br/seed/arquivos/pdf/tvescola/leis/D2494.pdf , Acesso em: 5 dez. 2017.

BRASIL. Decreto no 5.622/2005, de 19 de dezembro de 2005. Regulamenta o artigo 80 da Lei no 9.394, de 20 de dezembro de 1996, que estabelece as diretrizes e bases da educação nacional. Lex: Brasília, 2005. Disponível em:

http://www.planalto.gov.br/ccivil 03/ ato2004-2006/2005/decreto/d5622.htm Acesso em: 5 dez. 2017.

BRASIL. Decreto no 5.800/2006, de 8 de junho de 2006. Dispõe sobre o sistema Universidade Aberta do Brasil. Lex: Brasília, 2006. Disponível em: http://www.planalto.gov.br/ccivil 03/ ato2004-2006/2006/decreto/d5800.htm , Acesso em: 5 dez. 2017.

BRASIL. Lei no 10.172, de 9 de janeiro de 2001. Aprova o Plano Nacional de Educação e dá outras providências. Lex: Brasília, 2001. Disponível em:

http://portal.mec.gov.br/arquivos/pdf/L10172.pdf , Acesso em: 05 dez. 2017.

CRUVINEL, Fernanda. Et al. A dinâmica, os principais problemas e as qualidades no desenvolvimento de um curso de licenciatura em Educação Física na modalidade a distância. Pensar a Prática. Goiânia, v.18, n.3, jul./set. 2015.

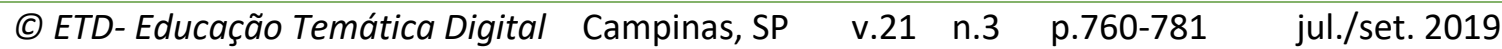


FREITAS, Helena Costa Lopes. Formação de professores no Brasil: 10 anos de embate entre projetos de formação. Educação e Sociedade, Campinas, vol. 23, n. 80, p. 136-167, set./2002.

GAWRYSZEWSKI, Bruno. CONFEF: organizador da mercantilização do campo da Educação Física. Dissertação (Mestrado em Educação) - Programa de Pós-Graduação em Educação, Faculdade de Educação, Universidade Federal do Rio de Janeiro, Rio de Janeiro, 2008.

GIOLO, Jaime. A Educação a Distância e a Formação de Professores. Educação e Sociedade, Campinas, vol. 29, n. 105, p. 1211-1234, set/dez. 2008.

INSTITUTO NACIONAL DE ESTUDOS E PESQUISAS ANÍSIO TEIXEIRA. INEP. Censo Escolar 2016: notas estatísticas. INEP/MEC: Brasília, fev. 2017. Disponível em:

http://download.inep.gov.br/educacao basica/censo escolar/notas estatisticas/2017/nota s estatisticas censo escolar da educacao basica 2016.pdf , Acesso em: 05 dez. 2017.

INSTITUTO NACIONAL DE ESTUDOS E PESQUISAS ANÍSIO TEIXEIRA. INEP. Sinopse Estatística da Educação Superior 2017 [online]. Brasília: Inep, 2018. Disponível em: http://inep.gov.br/sinopses-estatisticas-da-educacao-superior . Acesso em: 24 fev. 2019

INSTITUTO NACIONAL DE ESTUDOS E PESQUISAS ANÍSIO TEIXEIRA. INEP. Sinopse Estatística da Educação Superior 2015 [online]. Brasília: Inep, 2016. Disponível em: http://inep.gov.br/sinopses-estatisticas-da-educacao-superior , Acesso em: 05 dez. 2017.

INSTITUTO NACIONAL DE ESTUDOS E PESQUISAS ANÍSIO TEIXEIRA. INEP. Sinopse Estatística da Educação Superior 2012 [online]. Brasília: Inep, 2013. Disponível em: http://inep.gov.br/sinopses-estatisticas-da-educacao-superior , Acesso em: 05 dez. 2017.

INSTITUTO NACIONAL DE ESTUDOS E PESQUISAS ANÍSIO TEIXEIRA. INEP. Sinopse Estatística da Educação Superior 2009 [online]. Brasília: Inep, 2010. Disponível em: http://inep.gov.br/sinopses-estatisticas-da-educacao-superior , Acesso em: 05 dez. 2017.

INSTITUTO NACIONAL DE ESTUDOS E PESQUISAS ANÍSIO TEIXEIRA. INEP. Sinopse Estatística da Educação Superior 2006 [online]. Brasília: Inep, 2007. Disponível em: http://inep.gov.br/sinopses-estatisticas-da-educacao-superior , Acesso em: 05 dez. 2017.

LAZZAROTTI FILHO, Ari; PASQUALI, Dennia; FURTADO, Roberto Pereira. Quem ficou e o que ficou na formação do curso de Educação Física, licenciatura, na modalidade a distância. In: Congresso Brasileiro de Ciências do Esporte, 19., 2015, Vitória. Anais... Vitória: Colégio Brasileiro de Ciências do Esporte, 2015.

MALANCHEN, Julia. As políticas de formação inicial a distância de professores no Brasil: democratização ou mistificação? Dissertação (Mestrado em Educação) - Centro de Ciências da Educação, Universidade Federal de Santa Catarina, Florianópolis, 2007.

MANDELI, Aline de Souza. EAD e UAB: a consolidação da fábrica de professores em nível superior. In: EVANGELISTA, Olinda; SEKI, Allan Keji. Formação de professores no Brasil: leituras a contrapelo. Araraquara: Junqueira \& Marin, p. 197-232, 2017.

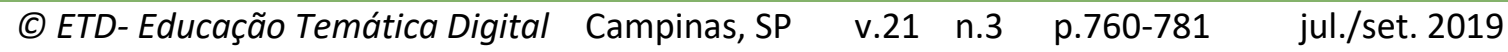


NOZAKI, Hajime. Educação Física e Reordenamento no Mundo do Trabalho: mediações da regulamentação da profissão. Tese (Doutorado em Educação) - Faculdade de Educação, Universidade Federal Fluminense, Niterói, 2004.

PIMENTEL, Fernanda Cruvinel. Et al. Formação de professores de Educação Física a distância: a experiência da Universidade de Brasília. Motrivivência. Florianópolis, v.26, n.43, p.55-69, dez./2014.

PIMENTEL, Fernanda Cruvinel; MASCARENHAS, Fernando. O cenário dos cursos de licenciatura em Educação Física a distância no contexto do sistema Universidade Aberta do Brasil. In: Congresso Brasileiro de Ciências do Esporte, 18., 2013, Brasília. Anais... Brasília: Colégio Brasileiro de Ciências do Esporte, 2013.

PIMENTEL, Fernanda Cruvinel. Et al. Expansão do ensino superior e formação profissional em Educação Física: um mapeamento dos cursos na modalidade de Educação a Distância. Pensar a Prática. Goiânia, v.16, n.4, p.1187-1201, out./dez. 2013.

SOBRINHO, José Pereira Sousa. Formação de professores na sociedade do capital: uma análise crítica das diretrizes curriculares nacionais para os cursos superiores de educação física. Motrivivência, Florianópolis, ano XXIII, n. 36, p. 129-148, jun./2011.

Revisão gramatical realizada por:

Aline Miranda Fonseca.

E-mail: alinemf11@gmail.com 